\title{
FABRICATION OF NANOHYDROXYAPATITE/ SCRAWL COLLAGEN/CHITOSAN COMPOSITE FOR BONE GRAFT CANDIDATE
}

\author{
S. E. Cahyaningrum ${ }^{1, *}$, N. Herdyastuti ${ }^{1}$, D. Supangat ${ }^{1}$, B. Devina ${ }^{1}$ \\ and M. Kurniasari ${ }^{1}$ \\ ${ }^{1}$ Department of Chemistry, Faculty of Mathematics and Natural Science, \\ Universitas Negeri Surabaya, Indonesia 60231 \\ *E-mail: saricahyaningrum@unesa.ac.id
}

\begin{abstract}
In this research, nanohydroxyapatite (HA) is combined with collagen (Coll) and chitosan (Chi) is expected to give a similar composition with bone. HA was mixed with chitosan solution and collagen with a mass ratio of the composition HA/Coll/Chi 7: 2: 1; 7: 1.5: 1.5; and 7: 1: 2 w/w. FTIR analysis showed a band $\mathrm{PO}_{4}{ }^{3-}$ and $\mathrm{OH}^{-}$ adsorption of $\mathrm{HA}$, as well as a shift wave number in the group $\mathrm{C}=\mathrm{O}$ and $\mathrm{NH}_{2}$ of the chitosan and collagen which shows there has been a bond between HA, chitosan and collagen. The decreased degree of crystallinity causing composites were more amorphous so that the composite with the highest content of collagen has a compressive strength of the smallest value. SEM analysis showed the surface morphology of composite HA/Coll/Chi consists small grain of regular arrangement.
\end{abstract}

Keywords: nanohydroxyapatite, scrawl collagen, chitosan, bone graft

(c) RASĀYAN. All rights reserved

\section{INTRODUCTION}

Bone as the network at human being body has a very important role, so that if bone happened damage will cause the problem of serious health. Basically, bone cells have the ability of remodeling alone, but require sufficient time. The process of remodeling the bone can be quickened to use graft bone ${ }^{1}$. Bone graft is representation material substitution of bone able to improve repair damage bone, bioactive and biocompatible $^{2}$. Good synthetic bone is graft bone which structurally composition and looks like with natural bone. Bone graft is a natural composite that consists of $30 \%$ organic material composed of collagen, glucosamine, glycoproteins and $70 \%$ inorganic material with the dominant material is hydroxyapatite. A condition which must fulfill by synthetic graft bone was can be accepted by the body or biocompatible and to the advantage of processes osteoconductive, osteoinductive, and bone ontogenesis ${ }^{3-}$ ${ }^{5}$. The character of bio-ceramic likes HA and phosphate tricalcium is brittle ${ }^{6}$ so that hydroxyapatite muchbeen mix with natural material. Composite of collagen- nanohydroxyapatite inculcated in human being body show the nature of osteoconductive which is better to be compared to monolitic hydroxyapatite and yield bone matrix classification which is same precisely ${ }^{7-8}$. Bone is mainly composed of nanohydroxyapatite, glucosamine, water and collagen fibers ${ }^{9-10}$. To complete the nature of mechanic HA can modify by enhancing polymer as filler. Some material used to filler such as gelatin, carbon nanotube, polycaprolactone, carboxymethylcellulose, montmorillonite cellulose and chitin ${ }^{11-12}$. In this research is nanohydroxyapatite crosslinked with chitosan and collagen produce bone graft with a mass ratio of the composition HA/Coll/Chi 7: 2: 1; 7: 1.5: 1.5; and 7: 1: 2 w/w similar with composition natural bone $70 \%$ inorganic material and $30 \%$ organic material. Collagens have the potential to add that function to promote the structural and physiological functions bone graft more effectively. In this study, collagen extracted from scrawl (Gallus gallus). Chitosan is one of the natural polymers that synthesis from chitin ${ }^{13}$. Chitosan has the potency to be used as filler in composite for bone tissue engineering making ${ }^{14-16}$. Chitosan has the character of bioresorbable, biocompatible, non-toxic, non-antigenic, and biofunctional of 
osteoconductive $^{17}$. The character of osteoconductive is chitosan can quicken the growth of osteoblas in composite HA-Chitosan so that can quicken forming of bone mineral.

\section{Material and Methods}

\section{EXPERIMENT}

The eggshells (Gallus gallus) as raw material for synthesis nanohydroxyapatite and scrawl (Gallus gallus) for synthesis collagen obtained from Sidoarjo, Indonesia. Chitosan with 85\% deacetylation degree was purchased from ChemIndo. Some reagents p.a quality purchase from Merck. Standart Hydroxyapatite was purchase from Bank Jaringan RS Dr. Sutomo, Indonesia.

\section{Synthesis of Nanohydroxyapatite-Chitosan}

Amount of chitosan was dissolved in of $2 \% \mathrm{v} / \mathrm{v}$ acetic acid solution was added with HA was suspended in water with wish drop method. The solution was stirred until homogeneous manner. The solution was then transferred to a small petri dish.

\section{Synthesis of Nanohydroxyapaptite-Chitosan- Scrawl Collagen}

The nanohydoxyapaptite- chitosan solution prepared as above was simultaneously and drop to drop was added with scrawl collagens. The mixture was stirred until homogeneous. Finally, this mixture was printed to a small plate dish, and then washes with demineralization water. The variation of the solution was added with a ratio of composition HA:Coll:Chi are 7:1:2; 7:1.5:1.5 and 7:2:1 (w/w).

The composite that produces from this synthesis is characterized by using FTIR to the identification of the functional group; X-ray Diffraction to see the formation and phase of crystals; Scanning Electron Microscopy (SEM) to see at the morphology of the material and UTM to determine the compressive strength.

\section{RESULTS AND DISCUSSION}

Spectra Fig.-1 showed some function group of the composite are $\mathrm{PO}_{4}{ }^{3-}$ and $\mathrm{OH}-$ from $\mathrm{HA}$, function group of $\mathrm{C}=\mathrm{O}$ and also $\mathrm{NH}_{2}$ of collagen and chitosan. At wave number around $3430 \mathrm{~cm}^{-1}$ overlaps with the vibration of $\mathrm{NH}$ and $\mathrm{OH}$ functional group. The wide spectra at wave number $3400,39 \mathrm{~cm}^{-1}, 3435,40$ $\mathrm{cm}^{-1}, 3435,47 \mathrm{~cm}^{-1}$ at a composite of $\mathrm{HA} / \mathrm{Coll} / \mathrm{Chi}$ represent vibration of $\mathrm{OH}$ from HA which is overlap with a functional group of $\mathrm{NH}_{2}$ of Chi and Coll, besides also effect of hydrogen bond that happened at the composite.

\begin{tabular}{|c|c|c|c|c|c|c|c|c|c|c|}
\hline \multirow[b]{2}{*}{ Sample } & \multicolumn{2}{|c|}{$2 \theta$} & \multicolumn{2}{|c|}{$2 \theta$} & \multirow[b]{2}{*}{$\begin{array}{c}\beta \\
(\mathrm{rad})\end{array}$} & \multicolumn{2}{|l|}{ Intensity } & \multicolumn{2}{|c|}{ Fraction of crystal } & \multirow[b]{2}{*}{$\begin{array}{c}\text { Crystallinity } \\
(\%)\end{array}$} \\
\hline & $\begin{array}{c}2 \theta_{1} \\
\left({ }^{\circ}\right)\end{array}$ & $\begin{array}{c}2 \theta_{2} \\
\left({ }^{\circ}\right)\end{array}$ & $\begin{array}{l}2 \theta_{1} \\
(\mathrm{rad})\end{array}$ & $\begin{array}{l}2 \theta_{2} \\
(\mathrm{rad})\end{array}$ & & $\begin{array}{l}\text { Amorf } \\
\text { (count) }\end{array}$ & $\begin{array}{l}\text { Crystal } \\
\text { (count) }\end{array}$ & Amorf & Crystal & \\
\hline HA & 33 & 35.2 & 0.56 & 0.59 & 0.019 & 63 & 5.030 & 1.099 & 57.368 & 98.09 \\
\hline $\begin{array}{c}\text { Composite } \\
\text { HA/Coll/ } \\
\text { Chi 7:2:1 } \\
\end{array}$ & 33.4 & 35.7 & 0.56 & 0.60 & 0.020 & 96.6 & 259.4 & 1.794 & 6.965 & 73.48 \\
\hline $\begin{array}{c}\text { Composite } \\
\text { HA/Coll/ } \\
\text { Chi } \\
7: 1.5: 1.5 \\
\end{array}$ & 33.6 & 35.9 & 0.56 & 0.61 & 0.022 & 31.4 & 100.3 & 0.616 & 5.075 & 77.19 \\
\hline $\begin{array}{c}\text { Composite } \\
\text { HA/Coll/ } \\
\text { Chi 7:1:2 }\end{array}$ & 33 & 35.6 & 0.55 & 0.60 & 0.022 & 5 & 25.25 & 0.063 & 0.764 & 88.16 \\
\hline
\end{tabular}

The interaction between collagen-HA seen from the friction of wave number and change of absorption intensity $1745 \mathrm{~cm}^{-1}$ of function group of $\mathrm{C}=\mathrm{O}$ carboxylate become $1637 \mathrm{~cm}^{-1}$ at each composite. The 
friction of this wave number effect of the existence of an interaction between function groups of carboxylate of collagen with ion of $\mathrm{Ca}^{2+}$ of HA. Interaction which possible happened at composite come from the interaction between ions of $\mathrm{Ca}^{2+}$ with functional group $\mathrm{NH} 2$ of chitosan.

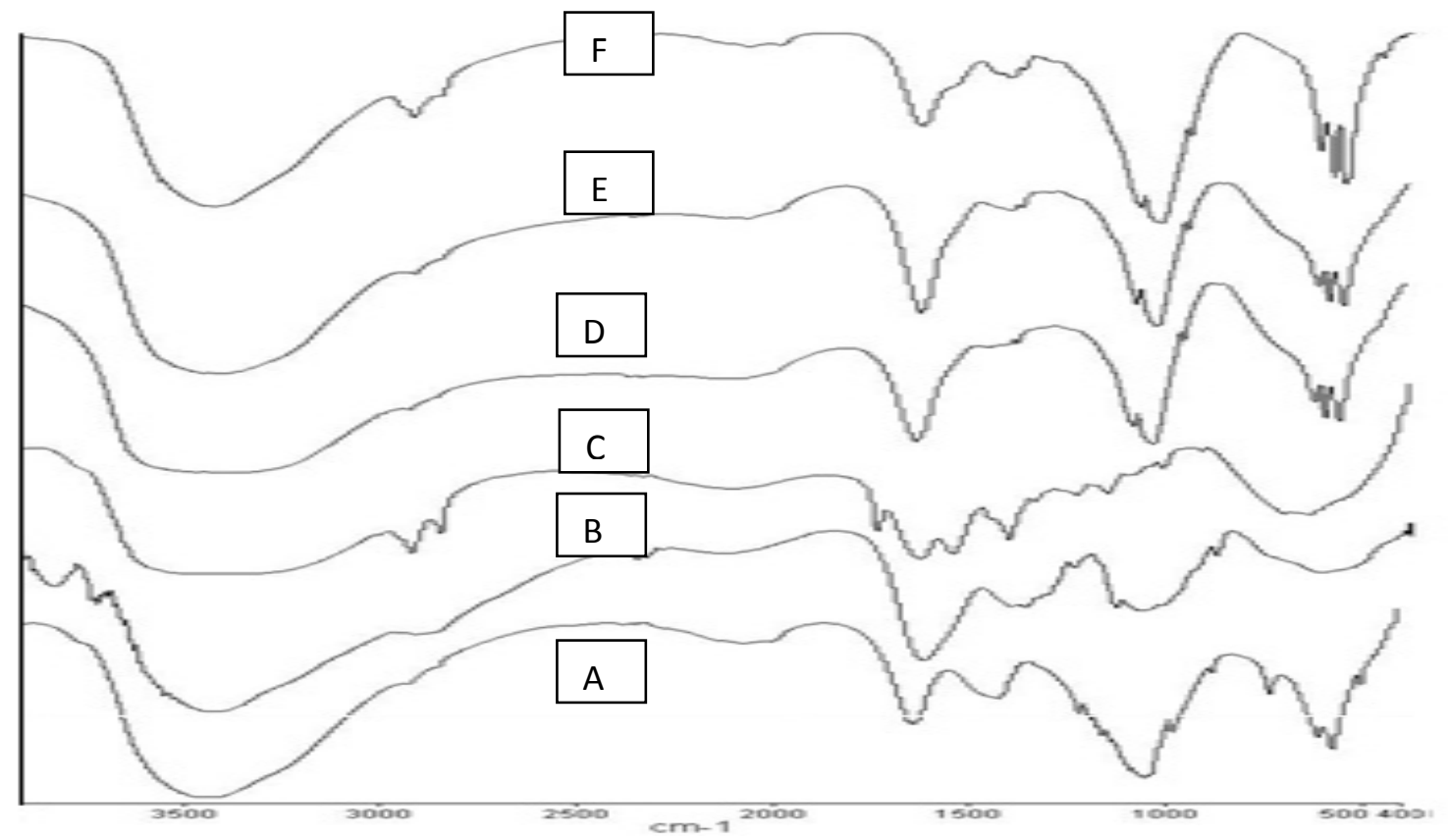

Fig.-1: Spectra FTIR HA (A), Chitosan (B), collagen (C), composite 7:2:1 (D); Composite 7:1.5:1.5 (E) and composite 7:1:2(F).

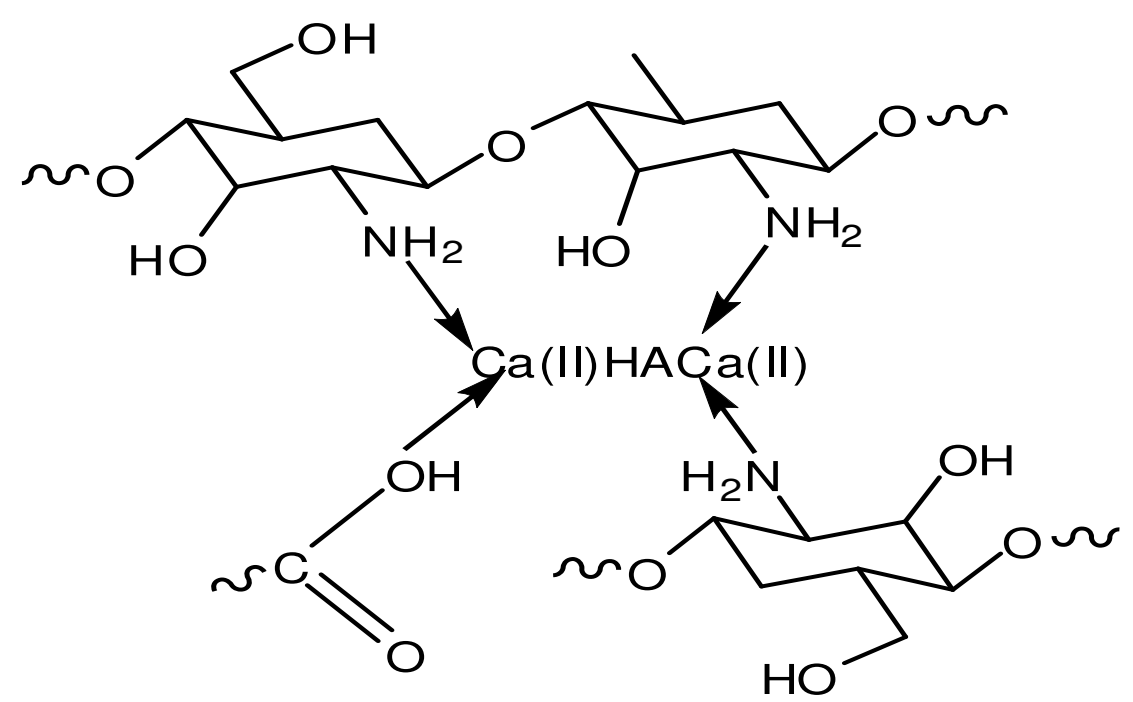

Fig.-2: Interaction hypothetic of Chitosan-Hydroxyapatite- collagen ${ }^{18}$.

Table-1 showed that crystallinity of composite HA/Coll/Chi smaller than crystallinity HA. This matter indicates that addition of organic material in the form of collagen and chitosan has an effect on crystallinity degree. Crystallinity degree showed that the number of crystal content in a material. Composite HA/Coll/Chi have crystallinity degree lower than HA caused by the addition of organic material at composite which result composite have the character of amorf. This matter can happen because collagen and chitosan have disseminated and bonded with apatite. The composite HA/Coll/Chi 7:2:1 lowest crystallinity among another composite. 
RASĀYAN J. Chem.

Vol. 11 | No. 2 |488 - 493 | April - June | 2018

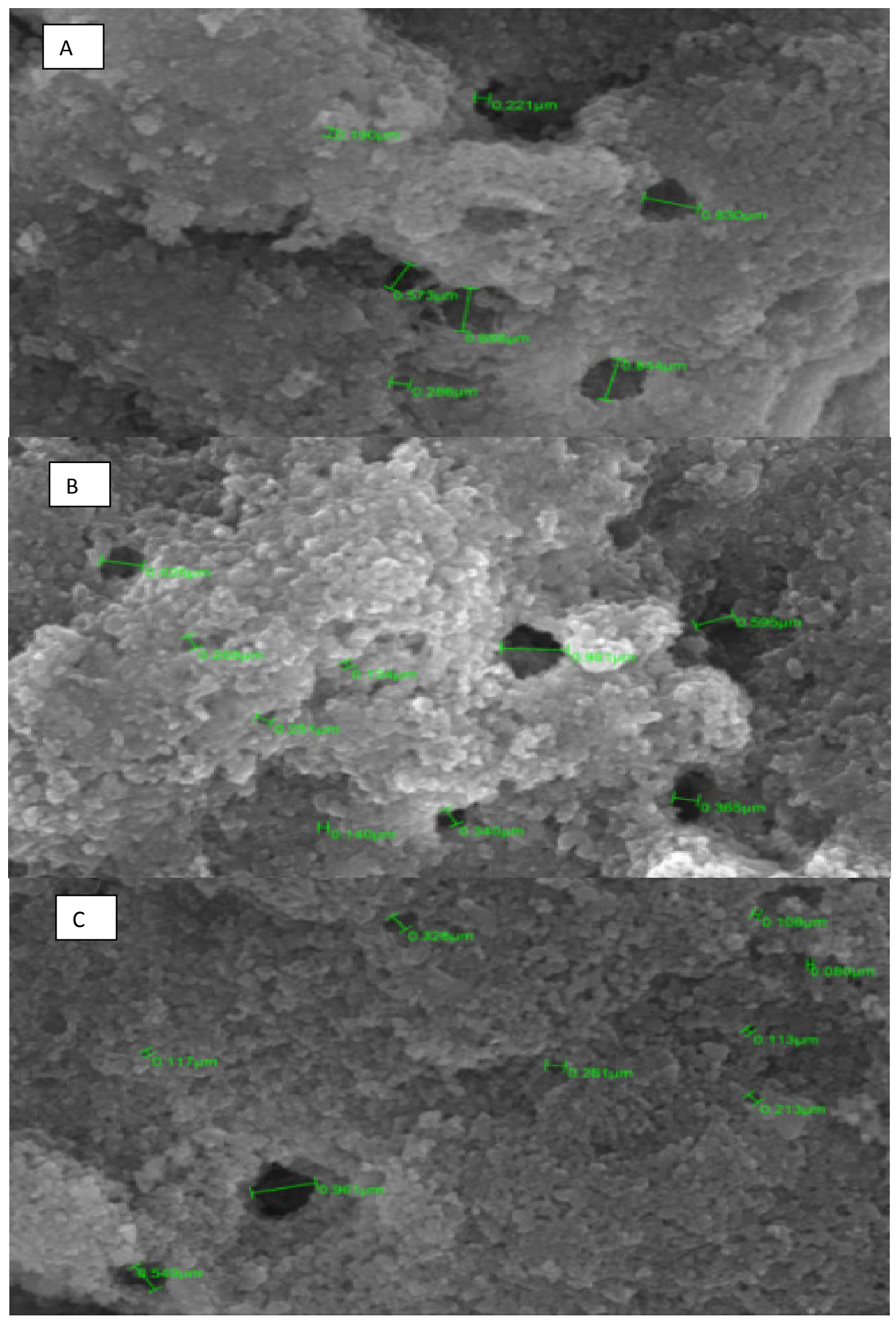

Fig.-3: Morphology of SEM: composite HA/Coll/Chi 7:2:1 (A) composite HA/Coll/Chi 7:1,5:1,5 (B) composite HA/Coll/Chi 7:1:2 (C) 10.000x 
This matter indicates that more and more collagen content hence it's it progressively lower because collagen represents organic material which has the character of amorf. The phase crystal identification was matched with the JCPDS and showed composite HA/Coll/Chi 7:2:1 produce a single phase of HA, composite HA/Coll/Chi 7:1.5:1.5 produce phase HA and calcium phosphate carbonate and then composite $\mathrm{HA} / \mathrm{Coll} / \mathrm{Chi}$ has produce $\mathrm{HA}$, calcium phosphate carbonate and calcium carbonate phosphate hidroxyde. Data Analysis of compressive strength of composite HA/Coll/Chi showed in Tables-2.

Table-2: The compressive strength of the composite

\begin{tabular}{c|c}
\hline Composite & Compressive strength $(\mathrm{kPa})$ \\
\hline HA/Coll/Chi $7: 2: 1$ & 147.27 \\
\hline HA/Coll/Chi 7:1.5:1.5 & 147.94 \\
\hline HA/Coll/Chi 7:1:2 & 186.57 \\
\hline
\end{tabular}

Pursuant to Table-2 obtained that composite HA/Coll/Chi with the content of chitosan at most owning value have compressive strength is biggest. Addition of organic material hence causing strength value depress downhill composite. The result of test compressive strength this proportional with a degree of crystallinity, progressively lower it is hence composite progressively amorf so that result of the test of compressive strength is low.

Figure-3 represents a composite picture of $\mathrm{HA} / \mathrm{Coll} / \mathrm{Chi}$, where is third draw seen apatite particle disseminate uniform through a matrix of collagen-chitosan. Surface morphology of composite $\mathrm{HA} / \mathrm{Coll} / \mathrm{Chi}$ consists of the formation of granular regular small, existence of formed pore. The circular yielded pore of the size which different each other and do not spread over to flatten is composite HA/Coll /Chi. Composite HA/Coll / Chi 7:2:1 owning pore of the size of 0.19-0.844 $\mu \mathrm{m}$. Composite HA/Coll/ Chi 7:1.5:1.5 owning pore of the size of $0.14-0.981 \mu \mathrm{m}$. At composite HA/Coll/Chi 7:1:2 owning pore of the size of $0.08-0.961 \mu \mathrm{m}$. Scaffold for technique engineer bone network needs pore structure and pore which each other to ascertain environment of biology supporting cell proliferation, the growth of tissue and existence of jetting of nutrition, the scaffold of the size pore more than $100 \mu \mathrm{m}$ support process infiltrate and cell proliferation. Pore size measure at matrix influenced by crystal amount and form of solution gelation during distribution and liofilization HA in the matrix.. Internal pore structure represents the result of from coagulation procedure. Composite macroporous formed HA-collagen with the method of freezedrying yield pore size measure which do not flatten, composite HA collagen with coagulation time during 2 hours yield biggest pore size measure ${ }^{19}$.

\section{CONCLUSION}

The composition of $\mathrm{HA} / \mathrm{coll} / \mathrm{chi}$ has effect in some characteristic of the composite. Composite composition influence value degree of crystallinity of composite, composite HA/Coll/Chi 7:2:1 with highest collagen content has the lowest degree of crystallinity that is $73.48 \%$. Test compressive strength shows that composite HA/Coll/Chi 7:2:1 yielding test the lowest value that is $147.279 \mathrm{Kpa}$. The composite HA/Coll/Chi 7:2:1 lowest crystallinity among another composite. Crystal phase analysis from XRD showed that composite HA/Coll/Chi 7:2:1 produce HA phase, composite HA/Coll/Chi 7:1.5:1.5 produce phase HA and calcium phosphate carbonate and then composite HA/Coll/Chi has produce HA, calcium phosphate carbonate and calcium carbonate phosphate hydroxide.

\section{ACKNOWLEDGMENT}

The researcher wishes thanks to DRPM DIKTI for support this research with Hibah Penelitian Berbasis Kompetensi Program 2017 No. Contract: 0001.88/UN38.11-P/LT/2017.

\section{REFERENCES}

1. S.K. Nandi, S. Roy, P. Mukherjee, B. Kundu, D.K. De \& D. Basu Indian Journal Medicine Reasearch., 132, 15 (2010)

2. S. Ramesh, K. L. Aw, R. Tolouei, M. Amiriyan, C. Y. Tan, M. Hamdi, J. Purbolaksono, M. A. Hassan, W. D. Teng Ceramics International., 39, 111(2013), DOI: 10.1016/j.ceramint.2012.05.103 
3. S. Bose, S. Dasgupta, S. Tarafder, A. Bandyopadhyay, Acta Biomaterialia., 6, 3782 (2010), DOI: 10.1016/j.actbio.2010.03.016

4. J. Liu, X. Ye, H. Wang, M. Zhu, B. Wang, Ceramics International., 29, 629 (2003), DOI: $10.1016 / \mathrm{S} 0272-8842(02) 00210-9$

5. Z. Huang, Y. Chen, Q. Ling F. W. Zhao, B. Yu, J. Tian, S. Jian Li, B.Miao Lin, Frontier Material Science., 5, 301 (2011), DOI: 10.1007/s11706-011-0142-4

6. A. Tathe, M. Ghodke, A. P. Nikalje International Journal of Pharmacy and Pharmaceutical Sciences, 2, 19(2010).

7. Z.W Qu, Q.G Meng, X. Xiao, B.L Li , F.M Zhang, Bio-Medical Materials and Engineering., 24, 683(2014), DOI: 10.3233/BME-130856

8. N. Jamarun, Z. Azharman, S. Arief, T. P. Sari, A. Asril, S. Elfina. Rasayan Journal of Chemistry. 8,133(2015)

9. Z. Huang, Q. Feng, B. Yu, S. Li. Materials Science and Engineering C.,31 683(2011), DOI: 10.1016/j.msec.2010.12.014

10. N.Jamarun, Z. Azharman, Zilfa, U. Septiani Oriental Journal Of Chemistry., 32.4.2095(2016), DOI: $10.13005 / \mathrm{ojc} / 320437$

11. F. Croisier, C. Jérôme European Polymer Journal., 49, 780 (2013), DOI: 10.1016/j.eurpolymj.2012.12.009

12. J. Venkatesan, Z .J Qian, B. Ryu, N. A. Kumar, S.K Kim. Carbohydrate Polymers., 83, 569 (2011), DOI: 10.1016/j.carbpol.2010.08.019

13. S. E. Cahyaningrum, and M. Monica, Bulletin Chemical reaction Engineering and Catalysis., 9, 263 (2014), DOI: $10.9767 /$ bcrec.9.3.7060.263-269

14. Charlena, A. Bikharudin, S. T. Wahyudi , Erizal. Rasayan Journal of Chemistry., 3, 766(2017), DOI: $10.7324 /$ RJC.2017.1031768

15. S Dhivya, S Saravanan, T P Sastry, N Selvamurugan. Journal of Nanobiotechnology., 13, 40 (2013) DOI: $10.1186 / \mathrm{s} 12951-015-0099-\mathrm{z}$

16. J. Venkatesan and Se-Kwon Kim Mar. Drugs., 8, 2252 (2010), DOI: 10.3390/md8082252

17. S. E. Cahyaningrum, N. Herdyastuti, A. Firdausa, D. Yanrita Rasayan Journal of Chemistry., 3, 959(2017), DOI: 10.7324/RJC.2017.1031635

18. C. Xianmiao., Y.Li, Y. Zuo Y, L. Zhang, J.Li, H.Wang Journal of Material Science and Engineering., 29, 29(2009), DOI: 10.1016/j.msec.2008.05.008

19. M. Z. Ichsan, Siswanto, D. Hikmawati. Journal of Physics and Application., 1, 89(2013).

[RJC-1916/2017] 